\title{
Seasonal dependence of the "forecast parameter" based on the EIA characteristics for the prediction of Equatorial Spread F (ESF)
}

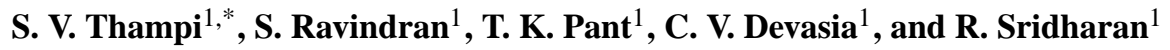 \\ ${ }^{1}$ Space Physics Laboratory, Vikram Sarabhai Space Centre, Trivandrum, 695022, India \\ *now at: RISH, Kyoto University, Japan
}

Received: 8 October 2007 - Revised: 26 December 2007 - Accepted: 17 January 2008 - Published: 25 June 2008

\begin{abstract}
In an earlier study, Thampi et al. (2006) have shown that the strength and asymmetry of Equatorial Ionization Anomaly (EIA), obtained well ahead of the onset time of Equatorial Spread F (ESF) have a definite role on the subsequent ESF activity, and a new "forecast parameter" has been identified for the prediction of ESF. This paper presents the observations of EIA strength and asymmetry from the Indian longitudes during the period from August 2005-March 2007. These observations are made using the line of sight Total Electron Content (TEC) measured by a ground-based beacon receiver located at Trivandrum $\left(8.5^{\circ} \mathrm{N}, 77^{\circ} \mathrm{E}, 0.5^{\circ} \mathrm{N}\right.$ dip lat) in India. It is seen that the seasonal variability of EIA strength and asymmetry are manifested in the latitudinal gradients obtained using the relative TEC measurements. As a consequence, the "forecast parameter" also displays a definite seasonal pattern. The seasonal variability of the EIA strength and asymmetry, and the "forecast parameter" are discussed in the present paper and a critical value for has been identified for each month/season. The likely "skill factor" of the new parameter is assessed using the data for a total of 122 days, and it is seen that when the estimated value of the "forecast parameter" exceeds the critical value, the ESF is seen to occur on more than $95 \%$ of cases.
\end{abstract}

Keywords. Ionosphere (Equatorial ionosphere; Ionospheric irregularities; Modeling and forecasting)

\section{Introduction}

The Equatorial Ionization Anomaly (EIA) and Equatorial Spread F (ESF) are two well known daytime and nighttime processes in the equatorial and low-latitude ionosphere thermosphere system. Both these processes have been investigated in quite detail through a number of ground and space based instruments (Rishbeth, 2000, and references therein).

Correspondence to: S. V. Thampi

(smithathampi@yahoo.com)
Many of these studies showed that the evolution of ionosphere through the daytime processes like EIA plays an important role in the generation of ESF.

The first indication of the significant role of EIA in the initiation of ESF was given by Raghavarao et al. (1988), where they showed that the large crest to trough ratio of EIA in the $270-300 \mathrm{~km}$ altitude range between 17:00 and 19:00 LT favored the occurrence of post sunset ESF. A similar association between EIA and ESF has also been shown in some later studies (Rama Rao et al., 1997). Sridharan et al. (1994) demonstrated that there exists a precursor in the OI $630 \mathrm{~nm}$ dayglow that represents the EIA strength, which enables the prediction of ESF at least $3 \mathrm{~h}$ prior to its actual onset. Using latitudinal distribution of TEC measurements at 20:00 LT it was shown that there is a high crest to trough ratio prevalent on ESF days (Valladares et al., 2001). It was also pointed out that the best available precursor for pre-midnight ESF is the EIA strength at sunset (Mendillo et al., 2001). From a limited sample of eight geomagnetically quiet nights, during September 1998, 85\% successful "forecasts" had been achieved by them using the strength of the EIA derived from GPS data for predictions. However, they speculated that the GPS derived proxy for electrodynamical vertical drift may turn out to be site and season dependent in its quantitative sense. It was also shown by Valladares et al. (2004), using differential TEC profiles, i.e. using the profiles of TEC (at 18:00 h) - TEC (at 20:00 h), that a fully developed pre-reversal enhancement (PRE) of the vertical drift (during nights of ESF activity) is able to reenergize the fountain effect. On similar grounds, Based on the Jicamarca digital ionosonde data and SCINDA $250 \mathrm{MHz}$ scintillation observations obtained by receiving signals from the FLEETSAT-7 geostationary satellite during July 1998-July 1999, Anderson et al. (2004) have demonstrated that there exists a threshold for the maximum $\boldsymbol{E} \times \boldsymbol{B}$ drift velocity (between 18:30 and 19:00 LT) of $20 \mathrm{~m} / \mathrm{s}$ that determines whether or not the subsequent UHF S4 values will be below or above 0.5.

Published by Copernicus Publications on behalf of the European Geosciences Union. 
Devasia et al. (2002) provided the missing link between EIA and ESF through meridional winds. They showed that during the equinoctial months when the base height of the F layer $\left(h^{\prime} F\right)$ at 19:00 IST is in the range of $270-300 \mathrm{~km}$, the meridional wind should be equatorward for ESF to occur over the equator. However, when $h^{\prime} F$ is $>300 \mathrm{~km}$ the ESF occurred irrespective of the polarity of the meridional wind. It was suggested that the observed equatorward winds could be an outcome of the pressure bulges associated with Equatorial Temperature and Wind Anomaly (ETWA) (Raghavarao et al., 1993), which in turn is linked to EIA (Devasia et al., 2002). Further, it was shown that the threshold $h^{\prime} F$ for the triggering of ESF irrespective of the polarity of the meridional wind has a linear relationship with solar activity (Jyoti et al., 2004; Manju et al., 2007). All these results conclusively established that EIA and ESF are related.

Recently, using the digisonde at Jicamarca and a chain of GPS receivers on the west side of America, it was observed that the seasonal variation in the ESF occurrence is associated with that in the PRE of $\boldsymbol{E} \times \boldsymbol{B}$ drift and EIA asymmetry (Lee et al., 2005). It was shown that the larger $\boldsymbol{E} \times \boldsymbol{B}$ drift $(>20 \mathrm{~m} / \mathrm{s})$ and smaller asymmetry $(<0.3)$ provide a preferable condition for the development of ESF. It was also reported that the seasonal variability of ESF occurrence is associated with those in the PRE $\boldsymbol{E} \times \boldsymbol{B}$ drift and EIA asymmetry (Lee et al., 2005).

In this context, Thampi et al. (2006) combined the effects of the daytime EIA strength and asymmetry in the time interval 16:00-18:45 LT to arrive at a combined parameter $(C)$ that could possibly define the background ionospheric conditions, in relation to the occurrence/non-occurrence of ESF. The parameter thus defined was used to "predict" the possible occurrence of post sunset ESF. Using the dataset spanning from August 2005-January 2006, it was shown that $C$ is systematically higher for ESF days. For that limited data set, representing autumnal equinox and winter of low solar activity period, it was shown that a single threshold value of $C=2$, clearly separates the ESF days (Thampi et al., 2006). The present paper describes the results using an extended database covering all the four seasons during a low solar activity period (from August 2005-March 2007), to delineate the seasonal variability of the EIA characteristics and the likely skill factor of the new parameter " $C$ ", which can serve as a forecast parameter for the occurrence/non-occurrence of ESF.

\section{Database}

The CRABEX receiver located at Trivandrum $\left(8.5^{\circ} \mathrm{N}, 77^{\circ} \mathrm{E}\right.$, diplat. $\sim 0.5^{\circ} \mathrm{N}$ ) basically receives the phase coherent signals of 150 and $400 \mathrm{MHz}$ transmitted from the NIMS (Navy Ionospheric Monitoring System) satellites, and measures the differential Doppler between them. This is a part of the Coherent Radio Beacon Experiment (CRABEX), in which a chain of 6 receivers in the $77-78^{\circ}$ E meridian is being operated, for ionospheric tomography. The details of converting the measured relative phase to the latitudinal profiles of relative vertical TEC is given by Thampi et al. (2005). For the present study the data for the period August 2005-March 2007 are used. The ESF, in our study refers to the occurrence of bottom side spread $\mathrm{F}$ as seen by the co-located ground-based ionosonde at Trivandrum, where the usual time of the onset of ESF is 19:15-19:45 IST (Indian Standard Time, +5.5 UT). In the delayed ESF cases (i.e. beyond 20:30 IST), the ESF observed at the site might be due to irregularities drifting into the field of view (Mendillo et al., 2001). However, it should be mentioned here that local conditions would also affect the onset time of ESF, and all the delayed ESF cases may not be due to drifting irregularities. However, since we have no means to discriminate the in-situ generated irregularities from those drifted into the field of view, the delayed ESF cases have not been considered here, since our aim is to quantify the role of background ionospheric conditions in local generation of ESF.

The TEC data in the time interval 16:00-18:45 IST has been chosen for the estimation of the C-parameter, whereas for studying the general features of the EIA, we have used the data in the time interval 11:30-14:30 IST, (as it is known that EIA is fully developed by 13:00-14:00 LT during low solar activity period (Sastri, 1990)). Owing to the fact that only $3-$ 4 satellites are being tracked, there are days when we do not have data within this specific time span of 16:00-18:45 IST. Further, it is not possible to get the data exactly at the same time on two consecutive days, since the NIMS satellites are polar orbiting. These are the inherent limitations of our data set itself. In the present study, data from satellite passes with maximum off axis elevation $>50^{\circ}$ only are selected. For estimating the latitudinal gradients we have used only the part of the data for which the direct elevation angles are $>35^{\circ}$, because the simple sec $\chi$ mapping will not hold good for lower elevation angles. This is the case especially in the equatorial and low latitude region, where large gradients in electron density exist.

\section{Results and discussion}

The seasonal variability of the EIA is shown in Fig. 1a. Each of the curves in Fig. 1a represents the seasonal mean of the latitudinal profiles of TEC using the data in the time interval 11:30-14:30 IST. It can be seen that during equinoxes, the EIA is the strongest and most symmetric, whereas in both winter and summer solstices, the EIA is much weaker, and significantly asymmetric (with stronger crest at the winter hemisphere), pointing towards the significant role of the trans-equatorial winds. These observations are also consistent with the latitudinal variations of TEC observed earlier, for example using ATS-6 (Davies, 1980, and references therein). It may be noted that the EIA shows asymmetry 


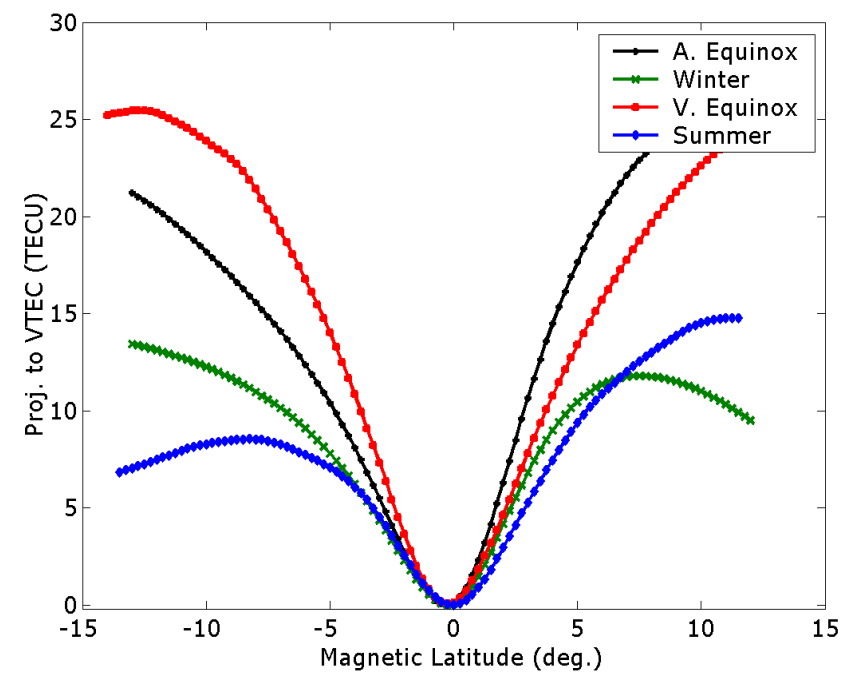

Fig. 1a. The seasonal variability of relative vertical TEC showing the variability in the EIA strength and asymmetry.

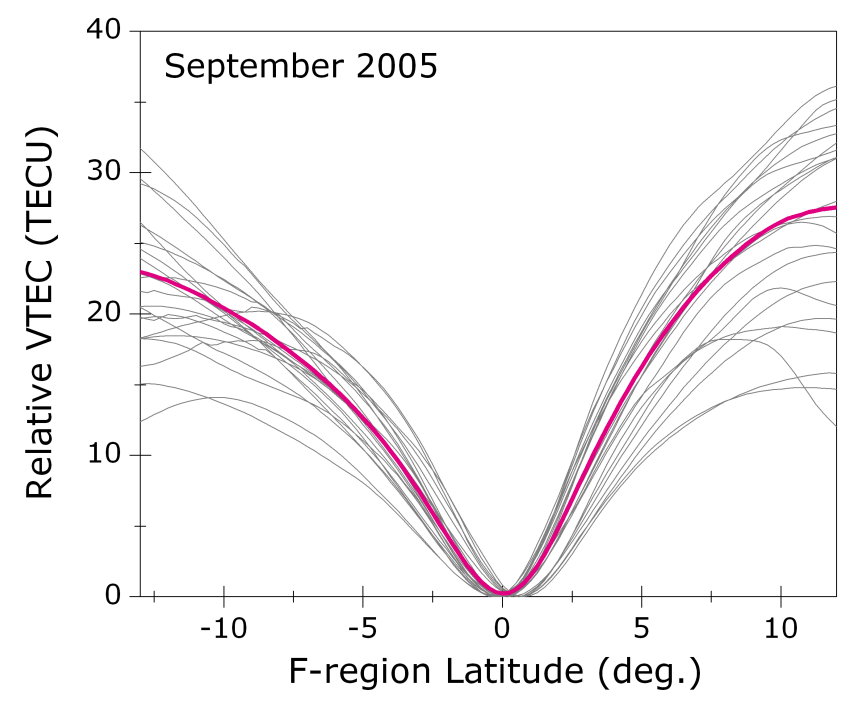

Fig. 1b. Latitudinal profiles of TEC in the time interval 11:3014:30 IST during September 2005. The thick pink curve shows the monthly mean.

about the dip equator even in the equinoctial months. This can be clearly seen in Fig. 1b, which shows the TEC curves for September 2005. The thick pink curve shows the monthly mean. We can see that EIA asymmetry is present to some extent, with significant day-to-day variability. However, when compared to the solstice months, we can see that the crests are stronger and located farther in latitude, whereas in solstice period the winter crest is located closer to the equator. It may be noted that it is this day-to-day variability in the EIA asymmetry, which acts as a proxy for estimating the importance of neutral dynamics in determining the occurrence/non-occurrence of ESF on a given day.

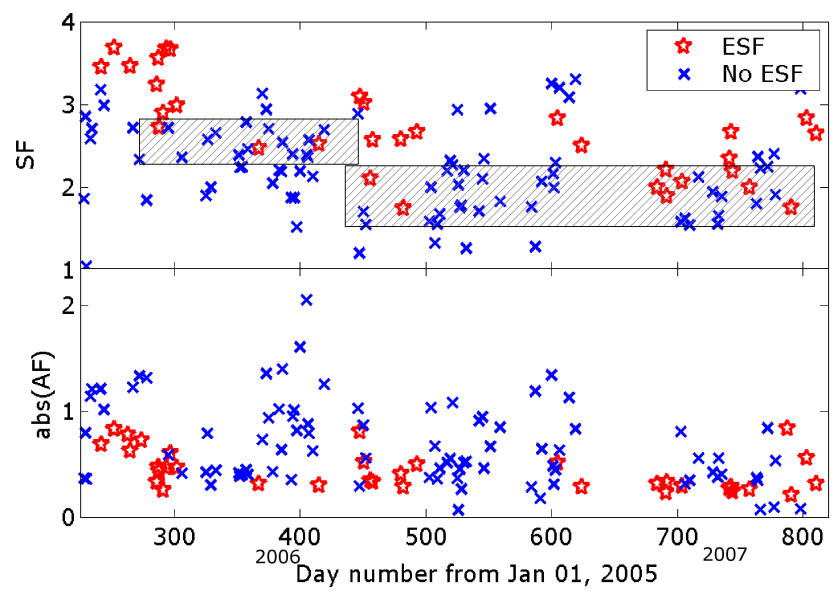

Fig. 2. Variation of EIA strength, $S_{F}$ (top panel) and asymmetry, $A_{F}$ (bottom panel) with day number. The shaded region in the top panel highlights the cases with similar $S_{F}$ values, with the occurrence of ESF (red) on a few days while the other days are without ESF (blue).

It is already known that the amplitude and direction of the thermospheric meridional (trans-equatorial) winds, have a significant control over the occurrence/non-occurrence of ESF on a given day. It has been shown by Maruyama (1988) and Mendillo et al. (1992) that a poleward wind would push the F-region ionization to lower altitudes along the magnetic field lines, which would enhance the conductivities at the lower altitudes, thereby loading the F-region dynamo field and hence the lifting of the F-layer will be inhibited resulting in the subsequent inhibition of the ESF activity. The symmetric/asymmetric nature of EIA has another important consequence also. The wind system related to ETWA, has wind velocity vector upward near the crests, equatorward between the crests and downward (converging) at the trough with the return flow somewhere in the dynamo region, when the EIA crests are symmetric with respect to the dip equator. However, when the EIA crests are asymmetric, with one of the crests significantly weaker than the other, the convergence would be away from the equator, closer towards the weaker crest. In that case, the contribution to downward wind from this ETWA related circulation at the equator would be much less. This could be significant in the context of the occurrence/non-occurrence of ESF. It should be mentioned here that the in-situ measurements and the theoretical simulations had shown that vertical winds have a major role in the growth of ESF (Raghavarao et al., 1987, 1999; Sekar and Raghavarao, 1987; Sekar et al., 1994; Sridharan et al., 1997). Sekar and Raghavarao (1987) had shown that a downward wind of $1 \mathrm{~m} \mathrm{~s}^{-1}$ could cause the same growth rate as a $200 \mathrm{~m} \mathrm{~s}^{-1}$ eastward wind at $260 \mathrm{~km}$, while $16 \mathrm{~ms}^{-1}$ downward wind at $300 \mathrm{~km}$ can be as effective as the gravitational term. Our observations indicate that the asymmetry in the EIA crests can be related to the variability associated 


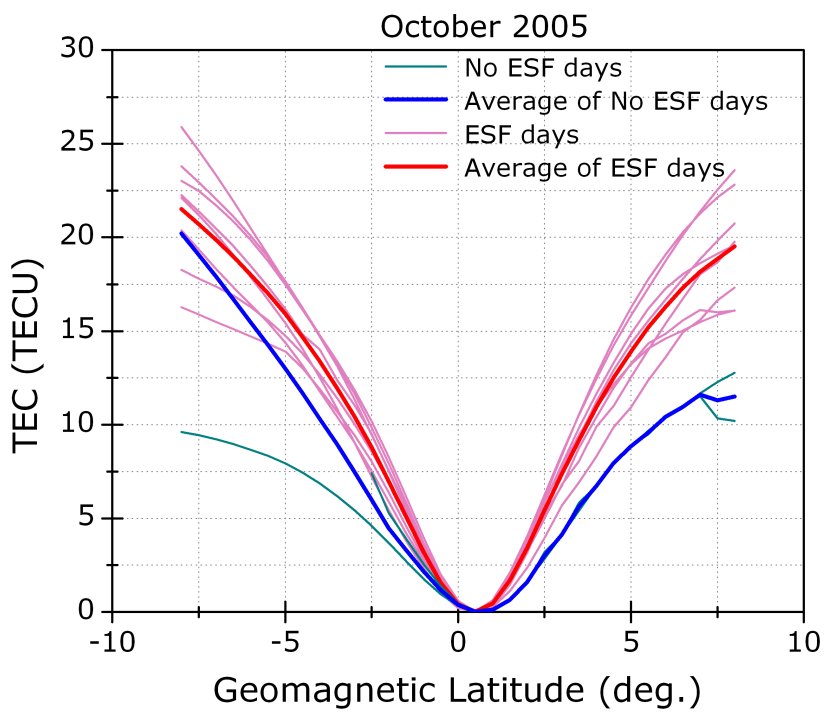

Fig. 3a. Comparison of the latitudinal profiles of relative vertical TEC for ESF and no-ESF days for October 2005.

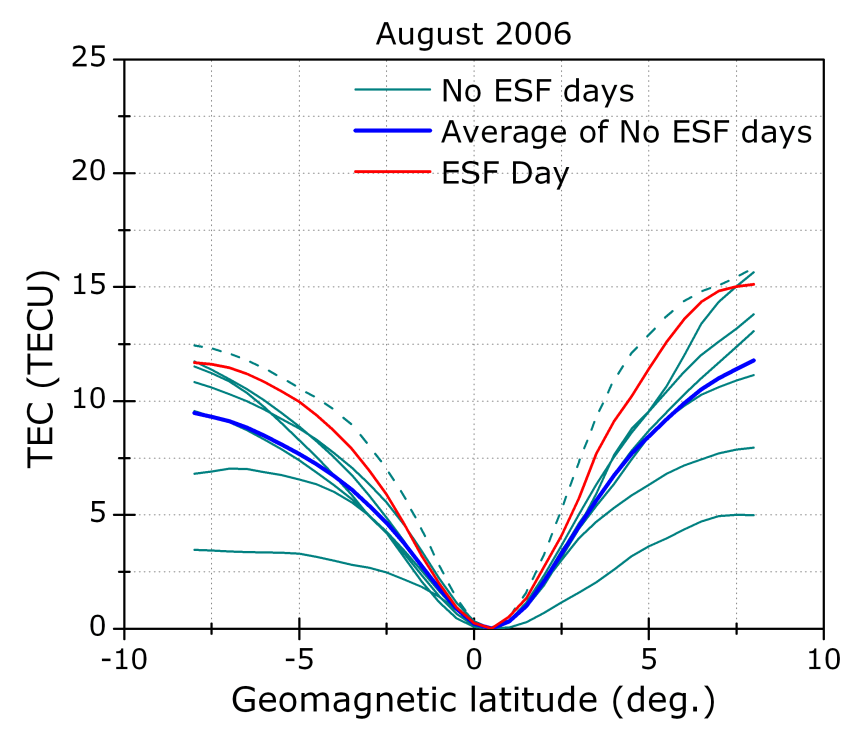

Fig. 3b. Same as Fig. 3a, but for August 2006.

with the ETWA related convergence at the equator, which in turn determines the magnitude of the vertical winds at the equator.

As mentioned earlier, the previous investigations were mostly focused on relating the EIA strength with the ESF occurrence, mainly using data acquired on one side of EIA. The acquisition of TEC data by CRABEX has the advantage of measuring the TEC on both sides of the EIA, which enables to include the effect of asymmetry also. Figure 2 shows the variation of EIA strength, defined as $S_{F}=\left(\frac{N+S}{2}\right)$ and EIA asymmetry, defined as $A_{F}=\left(\frac{N-S}{S_{F}}\right)$, where $N$ and $S$ represent the gradients (TECU/deg.) in the northern and

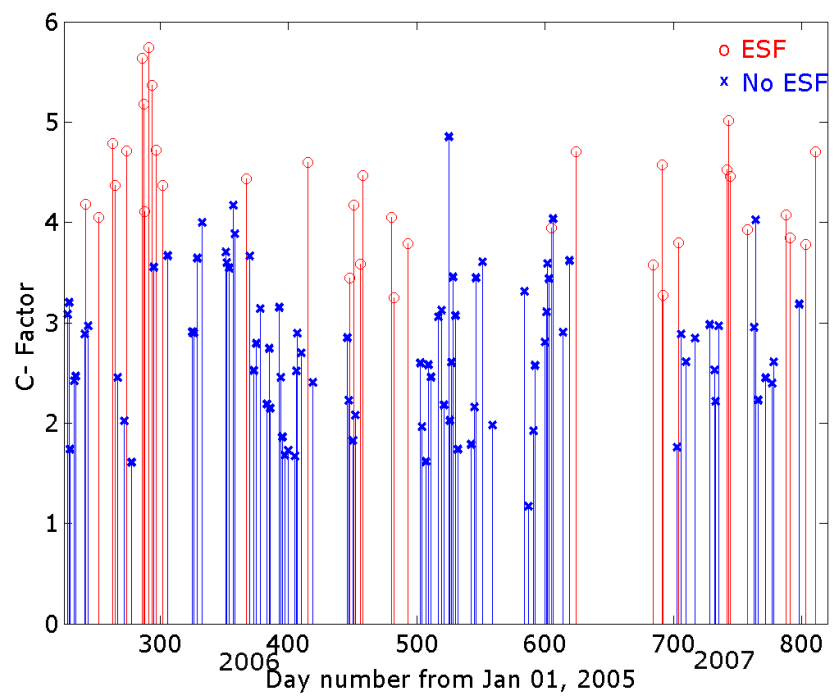

Fig. 4. Variation of $C$ with day number.

southern directions of the dip equator, estimated from relative TEC measurements. It can be seen that there are several days with ESF, even though the $S_{F}$ values are comparatively low (shaded region in Fig. 2 (top panel)). Similarly, Fig. 2 (bottom panel) shows that even though the low values of $A_{F}$ favors the presence of ESF, there are several cases with nearly equal values of $A_{F}$, with some of them being ESF days, while the others are not. It can be seen that we need to consider the combined effects of EIA strength as well as asymmetry.

Figure $3 a-b$ illustrates this fact more clearly, where the TEC profiles of ESF and no-ESF days of each month is plotted with their respective averages (if more than one day data is present). Figure 3 a shows the TEC profiles of ESF days (8 days) and no-ESF days ( 2 days) of October 2005 and their respective averages. It can be clearly seen that the average profile of days when ESF occurred is significantly more symmetric than that corresponding to the no-ESF days. Figure $3 b$ shows the TEC profiles of ESF day (only 1 day) and no-ESF days (7 days) of August 2006. We can see that the presence of ESF is favored by a strong and symmetric EIA. However, on one day (29 August 2006, shown as dotted curve), in spite of EIA being comparable to that on the ESF day (28 August 2006), the ESF is absent. The cause of this is not clearly understood. However, we can conjecture that one of the possible reasons could be the absence of "seeding perturbation" at F-region altitudes on this day.

In view of this, Thampi et al. (2006) formulated a new parameter, which incorporates the effects of the EIA strength and asymmetry and "predicts" the occurrence/nonoccurrence of ESF as early as 16:00 IST, which can define the state of the "background ionosphere" conducive for the generation of ESF irregularities much prior to its onset. When the asymmetry of EIA is greater than zero, this parameter has 


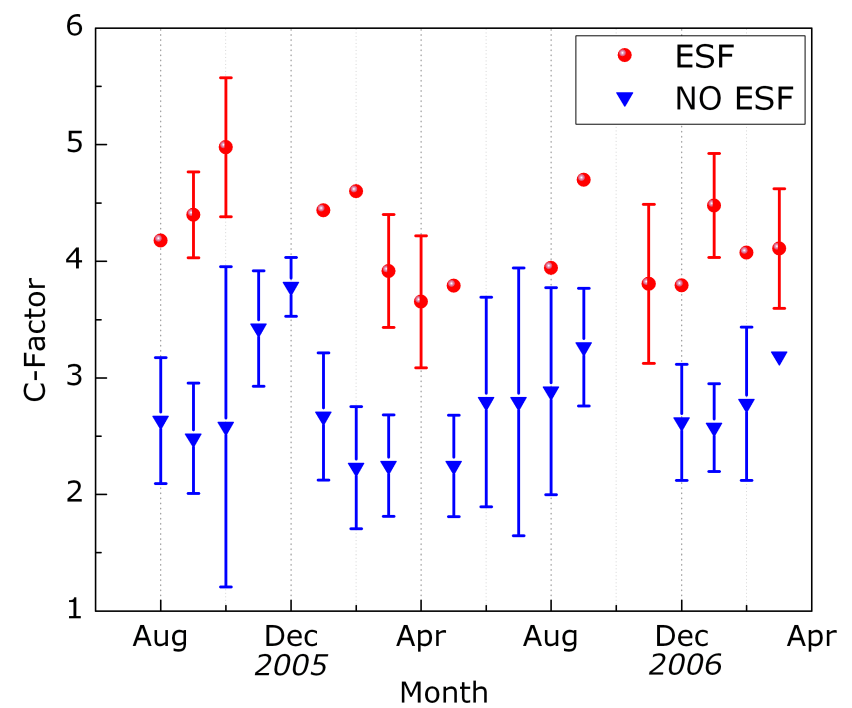

Fig. 5a. Monthly variation of $C$ for ESF and no-ESF days.

the form

$$
\begin{aligned}
C & =\sqrt{\frac{S_{F}}{\left|A_{F}\right|}} \\
& =\frac{S_{F}}{N-S}
\end{aligned}
$$

It has been shown that the combined parameter " $C$ " could explain the presence/absence of ESF on the days with similar values of $S_{F}$ (Thampi et al., 2006). Figure 4 shows the variation of $C$ with day number. It can be seen that even though " $C$ " is systematically higher for ESF days, it has a seasonal variability. It can also be seen that a single threshold value for " $C$ " can be identified for each season, so that when " $C$ " exceeds that particular threshold, ESF is seen to occur on that day. The seasonal dependence of the occurrence of ESF is also evident.

Figure 5a shows the monthly mean values of the C-factor for ESF days (Red) and Non-ESF days (Blue), with the corresponding standard deviations for each month. It can be seen that the mean values for the non-ESF days are distinctly lower than those for ESF days. Figure 5b shows the seasonal variation of the mean $\mathrm{C}$-factor. Here also, we can see that the C-factor for the ESF days is distinctly higher than those for non-ESF days. The seasonal averages have been estimated using the entire data set from August 2005 to March 2007, representing the low solar activity period.

Another important point, which is to be studied further, is the absence of ESF activity on the three days even though the " $C$ " values are relatively high (Fig. 4). Especially on 3 June, even with a " $C$ " value comparable for the ESF occurrence on equinoctial period, there was no ESF occurrence. Instead, blanketing Es was seen to persist over Trivandrum even during 19:45 IST (not illustrated). The occurrence of blanketing Es is also very common during the June-July period in the low-latitude ionosphere over Indian longitudes, in the solar

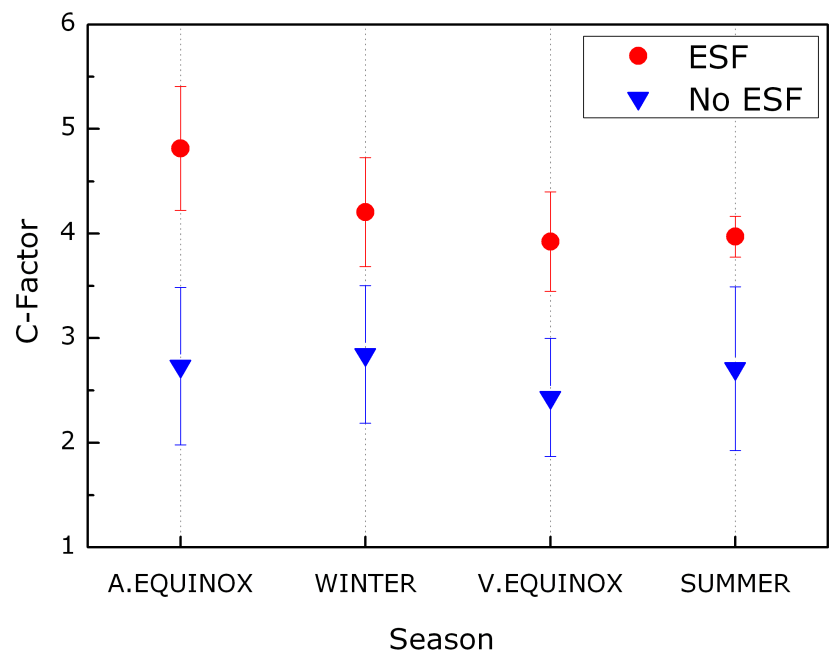

Fig. 5b. Seasonal variation of $C$ for ESF and no-ESF days.

minimum epoch (Devasia, 1976; Devasia et al., 2004). It is known that for estimating the growth rate, the field-line integrated ionospheric conductivity should be taken into account (Kelly, 1989; Sultan, 1996). The suppression of ESF activity by the finite E-region conductivity at the off-equatorial region is also reported earlier (Kelley et al., 2002; Abdu et al., 2003). The integrated E-region Pederson conductivity can be an important parameter in determining whether the bottom side F-layer will be stable against the R-T instability (Hanson et al., 1983). This particular aspect would be investigated further using a database of the blanketing Es at the off-equatorial region, the post-sunset height rise at the equator and the subsequent ESF activity. Similarly, on 29 August 2006 and 3 February 2007 also we can see that the C-Factor is comparable to that on near by ESF days, whereas the ESF is absent. These are to be investigated in detail considering other factors like the fraction of bottom-side electron content in the absolute TECs, the presence or absence of "seeding perturbation" etc. on these three days. It should also be noted that all the ESF events observed by the ionosonde could not be included in this study because of the unavailability of satellite passes at the required time interval on all days. This points out to the requirement of having more number of beacon satellites.

\section{Conclusion}

The observations of the strength and asymmetry of Equatorial Ionization Anomaly (EIA) using a ground-based beacon receiver located at Trivandrum $\left(8.5^{\circ} \mathrm{N}, 77^{\circ} \mathrm{E}, 0.5^{\circ} \mathrm{N}\right.$ dip lat) for a period spanning from August 2005-March 2007 are presented. It is seen that the seasonal variability of EIA strength and asymmetry are manifested in the latitudinal gradients obtained using the relative Total Electron Content (TEC) measurements. As a consequence, the "forecast 
parameter" used to predict the occurrence/non-occurrence of ESF on a given day that is derived using the strength and asymmetry of EIA (Thampi et al., 2006) also displays a definite seasonal pattern. In the present investigation, this seasonal pattern of the forecast parameter is discussed in detail, for the solar minimum epoch. It can be seen that the threshold values for the forecast parameter, above which ESF is seen to occur is slightly higher for solstice seasons than for equinox season. It should also be noted that over Indian longitudes, the ESF occurrence is generally less during the solstice period than during equinoxes. We have analyzed a total of 122 days (35 ESF days and 87 no-ESF days), among which the occurrence/non-occurrence of ESF was correctly delineated using the $\mathrm{C}$-factor except for three cases, which reiterates the fact that $\mathrm{C}$-factor can serve as a useful forecast parameter for the occurrence/ non-occurrence of ESF.

Acknowledgements. This work was supported by Department of Space, Government of India. One of the authors, Smitha V. Thampi, gratefully acknowledges the financial assistance provided by the Indian Space Research Organization through a research fellowship. The authors gratefully acknowledge L. Sarala and the other colleagues at Space Physics Laboratory, for their assistance in the data collection.

Topical Editor M. Pinnock thanks one anonymous referee for her/his help in evaluating this paper.

\section{References}

Abdu, M. A., McDougall, J. W., Batista, I. S., Sobral, J. H. A., and Jayachanddran, P. T.: Equatorial evening pre-reversal electric field enhancement and sporadic E layer disruption: A manifestation of E and F-region coupling, J. Geophys. Res., 108(A6), 1254, doi:10.1029/2002JA009285, 2003.

Anderson, D. N., Reinisch, B., Valladares, C., Chau, J., and Veliz, O.: Forecasting the occurrence of ionospheric scintillation activity in the equatorial ionosphere on a day-to-day basis, J. Atmos. Sol. Terr. Phys., 66, 1567-1570, 2004.

Davies, K.: Recent progress in satellite radiobeacon studies with particular emphasis on the ATS-6 radio beacon experiment, Space Sci. Rev., 25, 357-430, 1980.

Devasia, C. V.: Blanketing sporadic-E characteristics at the equatorial stations of Trivandrum and Kodaikanal, Indian J. Radio Space Phys., 5, 217-220, 1976.

Devasia, C. V., Jyoti, N., Viswanathan, K. S., Subbarao, K. S. V., Tiwari, D., and Sridharan, R.: On the plausible linkage of thermospheric meridional winds with equatorial spread F, J. Atmos. Sol. Terr. Phys., 64, 1-12, 2002.

Devasia, C. V., Jyoti, N., Subbarao, K. S. V., Tiwari, D., Reddi, C. R., and Sridharan, R.: On the role of vertical electron density gradients in the generation of type II irregularities associated with blanketing E S (E Sb) during counter equatorial electrojet events: A case study, Radio Sci., 39, RS3007, doi:10.1029/2002RS002725, 2004.

Hanson, W. B., Sanatani, S., and Patterson, T. N. L.: Influence of the E-region dynamo on Equatorial spread F, J. Geophys. Res., 88, 3169-3173, 1983.
Jyoti, N., Devasia, C. V. , Sridharan, R., and Tiwari, D.: Threshold height $\left(h^{\prime} F\right)$ c for the meridional wind to play a deterministic role in the bottom side ESF and its dependence on solar activity, Geophys. Res. Lett., 31, L12809, doi:10.1029/2004GL019455, 2004.

Kelley, M. C.: The earth's ionosphere: Plasma physics and electrodynamics, Academic Press, San Diego, Calif., 1989.

Kelley, M. C., Franz, T. L., and Prasad, G.: On the turbulence spectrum of equatorial spread F: A comparison between laboratory and space results, J. Geophys. Res., 107(A12), 1432, doi:10.1029/2002JA09398, 2002.

Lee, C. C., Liu, J. Y., Reinisch, B. W., Chen, W. S., and Chiu, F. D.: The effects of the pre-reversal drift, the EIA asymmetry, and magnetic activity on the equatorial spread $\mathrm{F}$ during solar maximum, Ann. Geophys., 23, 745-751, 2005, http://www.ann-geophys.net/23/745/2005/.

Manju G., Devasia, C. V., and Sridharan, R.: On the seasonal variations of the threshold height for the occurrence of equatorial spread F during solar minimum and maximum years, Ann. Geophys., 25, 1-7, 2007,

http://www.ann-geophys.net/25/1/2007/.

Maruyama, T.: A diagnostic model for equatorial spread F 1. Model description and applications to the electric field and neutral wind effects, J. Geophys. Res., 93, 14611-14622, 1988.

Mendillo, M., Baumgardner, J., Pi. Xiaoquing, Sultan P. J., and Tsunoda, R. T.: Onset conditions for equatorial spread F, J. Geophys. Res., 97, 13 865-13 876, 1992.

Mendillo, M., Meriwether, J., and Biondi, M.: Testing the thermospheric neutral wind suppression mechanism for day-to-day variability of equatorial spread F, J. Geophys. Res., 106, 3655-3663, 2001.

Raghavarao R., Gupta, S. P., Sekar, R., Narayanan, R., Desai, J. N., Sridharan, R., Babu, V. V., and Sudhakar, V.: Insitu measurements of winds electric fields and electron densities at the onset of ESF, J. Atmos. Terr. Phys., 49, 485-492, 1987.

Raghavarao, R., Nageswararao, M., Sastri, J. H., Vyas, G. D., and Sriramarao, M.: Role of equatorial ionization anomaly in the initiation of equatorial spread F, J. Geophys. Res., 93, 5959-5964, 1988.

Raghavarao, R., Hoegy, W. R., Spencer, N. W., and Wharton, L.: Neutral temperature anomaly in the equatorial thermosphere - A source of vertical winds, Geophys. Res. Lett., 20, 1023-1026, 1993.

Raghavarao, R., Suhasini, R., Mayr, H. G., Hoegy, W. R., and Wharton, L.: Equatorial Spread F (ESF) and vertical winds, J. Atmos. Sol. Terr. Phys., 61, 607-617, 1999.

Rama Rao P. V. S., Jayachandran, P. T., and Sriram, P.: Ionospheric irregularities, the role of equatorial ionization anomaly, Radio Sci., 32, 1551-1557, 1997.

Rishbeth, H.: The equatorial F-layer: Progress and puzzles, Ann. Geophys., 18, 730-739, 2000, http://www.ann-geophys.net/18/730/2000/.

Sastri, J. H.: Equatorial anomaly in F region - A review, Indian J. Radio. Space Phys., 19, 225-240, 1990.

Sekar, R. and Raghavarao, R.: Role of vertical winds on the Rayleigh-Taylor mode instabilities of the nighttime equatorial ionosphere, J. Atmos. Terr. Phys., 49, 981-985, 1987.

Sekar, R., Suhasini, R., and Raghavarao, R.: Effects of vertical winds and electrci fields in the nonlinear evolution of equatorial 
spread F, J. Geophys. Res., 99, 2205-2213, 1994.

Sridharan, R., Chandra, H., Das, S. R., et al.: Ionization hole campaign - a coordinated rocket and ground based study at the onset of equatorial spread F: first results, J. Atmos. Sol. Terr. Phys., 59, 2051-2067, 1997.

Sridharan, R., Pallam Raju, D., and Raghavarao, R.: Precursor to equatorial spread-F in OI $630.0 \mathrm{~nm}$ dayglow, Geophys. Res. Lett., 21, 2797-2800, 1994.

Sultan, P. J.: Linear theory and modeling of the Rayleigh-Taylor instability leading to the occurrence of equatorial spread F, J. Geophys. Res., 101, 26875-26891, 1996.

Thampi, S. V., Ravindran, S., Devasia, C. V., Pant, T. K., Sreelatha, P., and Sridharan, R.: First observation of topside ionization ledges using radio beacon measurements from low earth orbiting satellites, Geophys. Res. Lett., 32, L11104, doi:10.1029/2005GL022883, 2005.
Thampi, S. V., Ravindran, S., Pant, T. K., Devasia, C. V., Sreelatha, P., and Sridharan, R.: Deterministic prediction of post-sunset ESF based on the strength and asymmetry of EIA from ground based TEC measurements - Preliminary results, Geophys. Res. Lett., 33, L13103, doi:10.1029/2006GL026376, 2006.

Valladares, C. E., Basu, S., Groves, K., Hagan, M. P., Hysell, D., Mazzella Jr., A. J., and Sheehan, R. E.: Measurement of the latitudinal distribution of TEC during ESF events, J. Geophys. Res., 106, 29 133-29 152, 2001.

Valladares, C. E., Sheehan, R., and Villalobos, J.: A latitudinal network of GPS receivers dedicated to studies of equatorial spread F, Radio Sci., 39, RS1S23, doi:10.1029/2002RS002853, 2004. 